\title{
Designing a Citizen Science Project for Forest Landscapes: A Case from Hofmann Forest in Eastern North Carolina
}

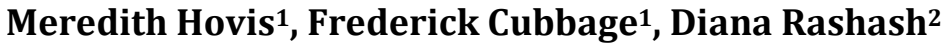 \\ ${ }^{1}$ North Carolina State University, Raleigh, NC, USA \\ ${ }^{2}$ North Carolina Cooperative Extension Service, Jacksonville, NC, USA \\ Email: mehovis@ncsu.edu,cubbage@ncsu.edu,diana_rashash@ncsu.edu
}

How to cite this paper: Hovis, M., Cubbage, F., \& Rashash, D. (2020). Designing a Citizen Science Project for Forest Landscapes: A Case from Hofmann Forest in Eastern North Carolina. Open Journal of Forestry, 10, 187-203.

https://doi.org/10.4236/ojf.2020.102013

Received: December 25, 2019

Accepted: February 14, 2020

Published: February 17, 2020

Copyright $\odot 2020$ by author(s) and Scientific Research Publishing Inc. This work is licensed under the Creative Commons Attribution International License (CC BY 4.0).

http://creativecommons.org/licenses/by/4.0/

\begin{abstract}
Citizen science is a participatory research design that utilizes both non-professional researchers and professional researchers to collect, analyze, and disperse data. Citizen scientists seek to discover answers and draw solutions to scientific questions. The Hofmann Open Water Laboratory (HOWL) project, established in 2016, focuses its collaborative-based efforts in eastern North Carolina. HOWL citizen scientists monitor water quality, and quantity, that flows on and off the Hofmann Forest. HOWL provides opportunities to citizen scientists and gathers data to meet the project outcomes, which include understanding the importance of Hofmann Forest in the inner coastal plain of North Carolina, building science education skills for citizen science participants, and enhancing community relationships between the forest and citizens. This article outlines several approaches for developing citizen science projects in a forest context, drawing on experiences from HOWL. The paradigm can be used to meet the needs of any forest landscape's research and management goals, while employing a participatory research approach. The guidelines present suggestions for productive and enduring processes for citizen engagement and project sustainability. Each project will need participants to set goals, build a diverse collaboration, and establish on-going evaluation processes to determine successful and failed components that ensures the project moves forward effectively. The citizen science efforts near the Hofmann Forest in Eastern North Carolina provided an excellent case study of the development of citizen science on the forest and adjacent lands. HOWL attempts to meet participant and socio-ecological outcomes, such as encouraging public action in natural resource and forest management, as well as enhancing scientific knowledge and skills. The project helps synthesize our experiences in this effort and the social science literature, providing reasonable
\end{abstract}


guidelines for those seeking to establish their own citizen science efforts within a forest context.

\section{Keywords}

Citizen Science, Forest Landscapes, Forest Context, Public Participation, Project Design

\section{Citizen Science in Forests}

Citizen science, also referred to as participatory research (Ballard et al., 2008; Shirk et al., 2012), is an integrative approach where non-professional researchers and professional researchers make observations and collect data across a range of geographic areas (Dickinson et al., 2010; Dickinson et al., 2012). Citizen scientists can also analyze the data and share their findings with other researchers, citizens, and communities (Bonney et al., 2009a). Conventional science practices, where academic, governmental, or commercial organizations are paid to conduct research, are comparable to citizen science practices. Both conventional science and citizen science processes are utilized to achieve various research questions and goals, and the results are used for decision-making, management, and education (McKinley et al., 2017).

Citizen science project designs can range across a spectrum of participation intensities and offer many types of activities for participants (Haklay, 2013; Vohland et al., 2019). Bonney et al. (2009a) discuss three types of citizen science project designs: co-created projects, collaborative projects, and contributory projects. The three project designs vary on the level of participant involvement and the specific activities citizen scientists perform (Figure 1), yet each involves citizen scientists to collect large quantities of data at scales that professional researchers are unlikely to collect alone (Burns et al., 2014).

Co-created projects are the rarest among the three types. Such projects are designed jointly by professional researchers and non-professional researchers. Projects that are co-created integrate both types of researchers to satisfy the duties of every step in the scientific process (e.g., Grassroots Project (Ramirez-Andreotta et al., 2015)). Collaborative projects are developed by professional researchers and give responsibility to non-professional researchers to collect data, analyze the data, and share the findings (e.g., The Great Arizona Mosquito Hunt (Tarter et al., 2019)). Contributory projects, the most common of the project types, are designed by professional researchers. Projects of this type delegate data collection and observations to non-professional researchers (e.g., Clark's Nutcracker Project (Tyson, 2019)) (Bonney et al., 2009a).

Many citizen science projects are developed to meet scientific outcomes (Bell et al., 2008); however, some are created to increase community networking, build community engagement, assist policy implementation and decisionmaking processes, increase participants' perceptions of stewardship, and 


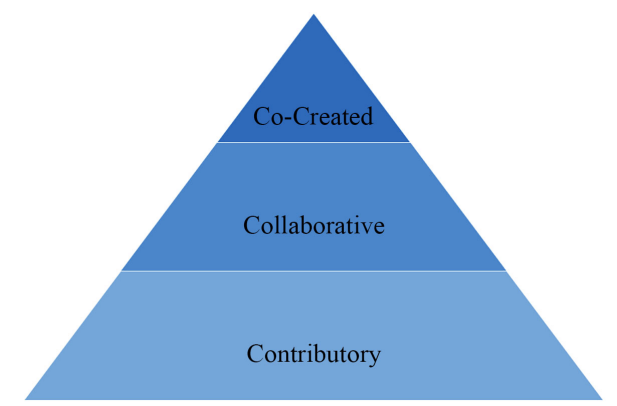

Figure 1. Three types of citizen science projects, with more intense participant involvement increasing up the pyramid.

enhance environmental education (Cooper et al., 2007; McKinley et al., 2017; McGreavy et al., 2016; Ottinger, 2009). Citizen science efforts commonly strive for at least one of three different outcomes: scientific, participant, and socio-ecological.

Research outcomes for citizen science refer to the discoveries found by citizens' data and results, such as any water quality and quantity trends and the abundance of benthic macro-invertebrates. Citizen science projects can be designed to meet outcomes of specific interest to the citizen scientist participants. For HOWL, participants gained new knowledge of scientific procedures or built skills of community collaboration and networking. Socio-ecological outcomes can include utilizing the citizen science results for decision-making, management, and enhancing relationships between humans and the environment (Shirk et al., 2012). All three outcomes can be adapted or refined as the project progresses.

Citizen science efforts alter the traditional scheme of forest and natural resource management, monitoring, and education. Current and previous citizen science projects have been implemented in many forest contexts to meet specific management objectives. Implementation of citizen science on forest lands allow local community members to access the lands, ask questions, solve problems, and learn about forest ecosystems and their benefits. A search of the literature provided various projects in a forest context that are designed to meet scientific, participant, or socio-ecological outcomes.

The study by Hawthorne et al. (2015) included both scientific and socio-ecological outcomes. The researchers utilized citizen science practices to monitor invasive species abundance in an urban forest. Their findings prioritized areas for native plant restorations that can be used for management efforts (i.e., scientific outcomes), and established a public, geospatial database that citizen scientists can adapt to their respective regions, thereby saving costs otherwise spent on paid contractors (i.e., socio-ecological outcomes). Ingell \& Pressier (2011) also employed citizen science approaches by identifying native tree species that survived non-native insects and pathogens in Virginia (USA), resulting in a scientific outcome. They established stocks of trees in the region that endured the invasive pests and the potential indicators for tree survival. 
Citizen science efforts have also been used to make forest management decisions by federal governments, such as US Forest Service and US Fish and Wildlife Service (McKinley et al., 2012; Pitt \& Schultz, 2018), and influenced conservation, environmental policy, and decision-making (i.e., socio-ecological outcomes) (McKinley et al., 2012). Citizen science projects in a forest context can also yield participant outcomes. These studies show increased engagement in natural resources and future careers, activism, literacy, and education (Krasny \& Doyle, 2002; Phillips et al., 2018; Pitt \& Schultz, 2018; Schusler \& Krasny, 2008).

Citizen science projects and their activities are utilized in various ways, within a forest landscape, to meet different outcomes. From ecological and forest monitoring on National Forests (e.g., Montana Youth Forest Monitoring Program (Pitt \& Schultz, 2018) to water monitoring in North Carolina's Hofmann Forest, citizen science leverages local volunteers and community groups to ask questions, draw solutions, and report findings. Not only do the data and findings produce scientific outcomes, they also provide participant and socio-ecological outcomes. Citizen science programs can be developed around many desired outcomes.

This paper discusses the importance of designing and implementing different types of citizen science projects on forest landscapes. We used our experiences with events in and around the Hofmann Forest in eastern North Carolina, as a case study to explain how citizen science projects can be established or adopted by other programs in a forest context. Literature of other citizen science projects that occur on forest landscapes and their outcomes for science, citizens, and the community is also included.

\section{Case Study: Hofmann Open Water Laboratory}

The Hofmann Forest, founded in 1936, is a North Carolina State University Foundation 79,000-acre education and research forest (North Carolina State University, 2017). The Hofmann Forest landscape, comprised of wetlands, agriculture, and forests, is the country's largest university forest. It contains a large variety of flora and fauna, including vulnerable and keystone species, such as the Venus flytrap (Dionaea muscipula) (US Fish \& Wildlife Service, 2018). Hofmann Forest is in eastern North Carolina, within Onslow and Jones counties (Figure 2).

The Hofmann Forest is a coastal pocosin-which means it is a swamp on a hill, shaped like an immense elongated bowl. As such, it catches, holds, and stores precipitation; cleanses runoff water that flows to the surrounding areas and the nearby ocean; and provides for some aquifer recharge. As its name indicates, the local Coastal Plain is quite flat, but like most pocosins, the Hofmann is one of the highest points in the region, with some elevations exceeding the relatively high level of 30 feet. The Hofmann's elevated bowl physiography helps it serve as the primary or partial fount for three rivers-the White Oak, the New, and the Trent. 


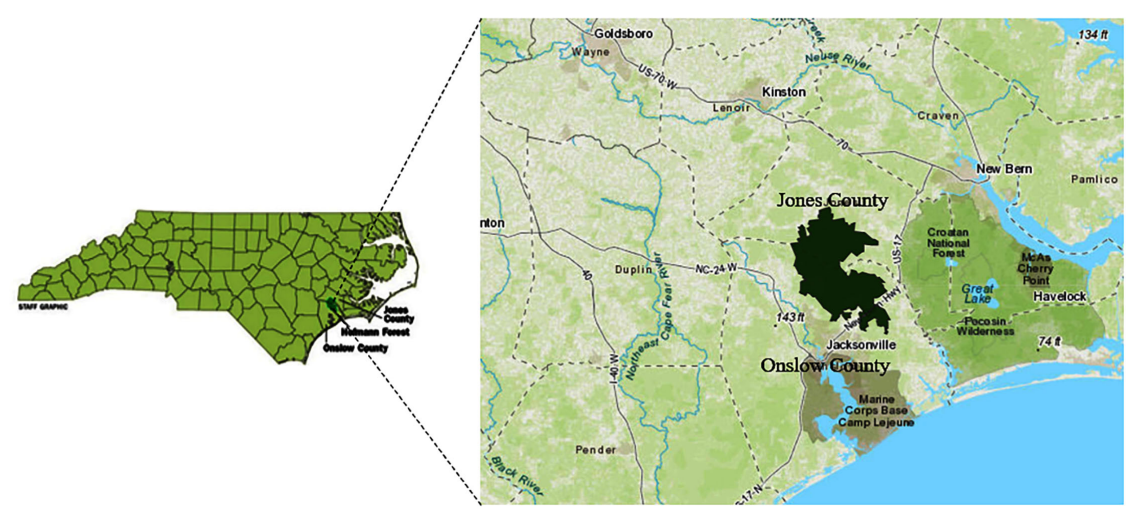

Figure 2. Location of Hofmann Forest in Jones and Onslow Counties, NC.

The Hofmann Forest is an intensively managed working forest, with 55,000 acres of planted pine forests and 24,000 acres of original deep swamp. The forest was extensively ditched and drained until the 1970s, and water levels on the forest are actively managed through a large system of ditches and water control structures (e.g. flashboard risers). The water emanating from the forest is usually considered to be very high quality in contrast to the adjacent agricultural and developed lands. The citizen science efforts were designed to examine this hypothesis and to engage both local conservation groups and citizens in natural science research and education.

HOWL is a co-created citizen science project developed by a team of researchers at NC State University (NCSU), NC Cooperative Extension Service (NC CES) scientists, and local conservationists. The initial HOWL citizen science efforts started when the NC State University Endowment Fund proposed to sell the Hofmann forest to commercial interests. The proposal prompted a few university faculty and local groups to start citizen science engagement as one means to help foster interest in protecting the forest in its managed and natural state (Cubbage et al., 2016; Montgomery \& Sutherland, 2016). In August 2016, the research team designed the project to enable citizens to develop research questions of Hofmann's importance in NC's inner-coastal regions, collect data, and test hypotheses about water quality. Initial participants recruited other community members and groups, in the coastal region, to join in the collaborative efforts. After a year, HOWL grew to include NCSU students and professors, local eastern NC conservation and environmental nonprofit organizations, NC CES 4-H youth and staff, Scout groups and leaders, homeschool students and instructors, and other interested individuals.

In the Fall of 2017, HOWL hosted a kick-off event to officially launch the project. The event occurred at White Oak River Campground, located in Jones County near the Hofmann Forest. Approximately 60 interested individuals attended. The participants collected water samples and searched for benthic macroinvertebrates in the White Oak River, New River, and Trent River, which flows through and off the forest. In 2018, HOWL hosted six monitoring field days, hosting 50 citizen scientists. As of 2019, the leadership team continues to 
host events for citizen scientists to learn skills and gather water monitoring data. School teachers and 4-H youth have shown the greatest interest and participation. Events are most often held during the summer months, presenting the opportunity to youth in fourth grade and higher. In the Spring of 2019, a local teacher and his class sampled one of the streams near their school, using the HOWL protocols. He relayed that the students were very engaged, it helped re-enforce what they learned in class, and that he plans to continue to monitor the site.

\section{Institution-Building: Steps for Designing a Citizen Science Project}

Based on our HOWL experiences and the literature, we synthesized institution-building guidelines for developing citizen science projects for natural resource conservation and environmental education programs. These ten steps can be adapted and applied to meet the needs of various types of forestry research projects (Figure 3). Our suggestions draw from citizen science strategies established by researchers at the Cornell Lab of Ornithology (CLO). CLO researchers manage many citizen science projects, attracting participants from across the nation. The CLO lab members design projects to answer scientific questions, while informing the public on ecological systems (Bonney et al., 2009b).

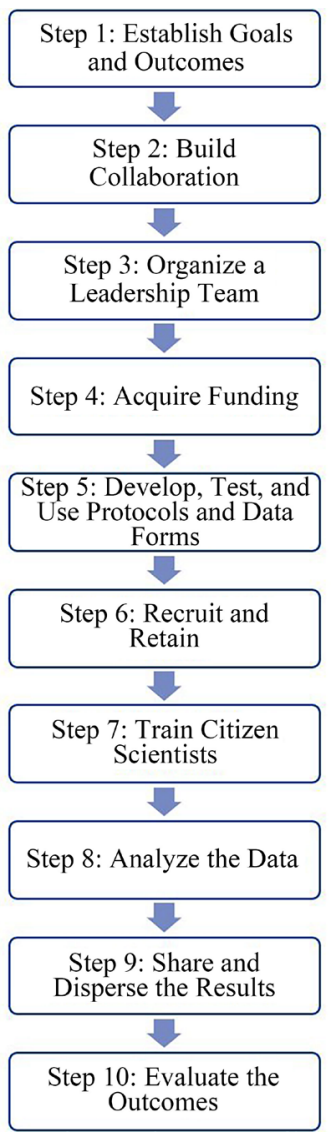

Figure 3. Ten steps in citizen science. 


\section{Step 1: Establish Goals and Outcomes}

Citizen scientists must recognize the shared goal among all collaborators (Davies \& White, 2012; Walpole et al., 2017). The project should center on a few research questions that citizen scientists will seek to answer. The team should recognize the concerns at stake and how citizen science approaches can be used to assess the issue. The team should express what specific outcomes the project intends to meet. It is also crucial to recognize what type of citizen science project will be developed; either co-created, collaborative, or contributory. For each project design, the activities and goals will vary (Shirk et al., 2012).

In January 2013, the NCSU Endowment Fund and Natural Resources Foundation initiated a proposed sale of the Hofmann Forest (Cubbage, Roise, \& Sutherland, 2016). The proposed sale prompted a collaboration among local community members, coastal conservation groups, school groups, and other interested individuals to save the property. In 2015, the decision was announced to retain the forest. The citizens' collaborative efforts and actions to save the Hofmann Forest prompted additional, and continued, involvement at the Hofmann to solidify its value and importance within the coastal community. The triggering event of the proposed sale stirred the group to stay connected and become more involved with the forest.

The citizen scientists decided to monitor the water quality and quantity of the rivers that run into and off the forest. Citizen scientists recognized the urgency for this project, as surface water quality in eastern $\mathrm{NC}$ is at risk of degradation due to deforestation, sea-level rise, substantial development, agricultural expansion, and concentrated animal feeding lots (Edwards \& Driscoll, 2008; Huffman \& Westerman, 1995; Government Accountability Office, 2008; US Geological Survey, 2018). Some chemical and physical metrics are monitored among state, federal, and county agencies; however, collection sites are sparse. Therefore, citizen science programs focus on leveraging monitoring efforts for enhanced regional coverage, as well as determine the water quality, and quantity, of the three rivers that flow off the Hofmann Forest.

\section{Step 2: Build Collaboration}

A citizen science team should consist of individuals who can contribute alternative perspectives and possess a variety of areas of expertise (Bennett et al., 2010). The establishment of collaboration, including various disciplines and interests, brings innovative ideas, solutions, and outlooks that assist in achieving an overarching goal (Walpole et al., 2017). If possible, such collaborations should involve multicultural and multigenerational perspectives in planning and decision-making processes (Blair et al., 2018; Watkins et al., 2018; Wondolleck \& Yaffee, 2000). The collaboration of diverse ideas, backgrounds, and skills from each organization and member helps to create a valuable citizen science research project.

Typically, a collaboration begins when individuals face a similar goal or mission. For HOWL, members shared common interests in environmental education and stewardship that revolved around their unique inner-coastal commu- 
nity and the iconic Hofmann Forest. Superordinate goals help find solutions to shared problems and aid in effective collaboration. Public involvement in communication and management will also result in more meaningful, useful, and enduring decision-making processes (Wondolleck \& Yaffee, 2000).

\section{Step 3: Organize a Leadership Team}

It is necessary to establish a multi-disciplinary leadership team that will serve as an advisory committee (Bonney et al., 2009b; Wondolleck \& Yaffee, 2000). The leadership team is then available to discuss, evaluate, and make recommendations about desired decisions. Ideally, each member of the team obtains an assigned role. For example, an educator should be available to provide information about water monitoring protocols and procedures. A data statistician or analyst should acquire, analyze, and visualize the data that the citizen scientists collect. A webmaster may be needed to update the social media entries and websites. Lastly, an evaluator would work to ensure that the project has measurable outcomes and is sustainable for the future (Bonney et al., 2009b). Like the entire collaboration, it is important that the leadership team includes members across disciplines and expertise (Stern \& Predmore, 2012; Watkins et al., 2018).

The HOWL leadership team is composed of NC CES staff, NCSU graduate students and faculty, Boy Scout leaders, homeschool teachers, and leaders of local conservation and environmental organizations. The leaders collaborate and carry a managing role in the project, acting as representatives from their respective organization. They lead citizen scientists in data collection and assist in training sessions. The leaders are also responsible for gathering all data sheets at the end of a fieldwork day.

\section{Step 4: Acquire Funding}

A successful citizen science project requires employed staff members to direct and manage project development, support and recruit participants, and analyze and curate data. Financial resources are necessary to sustain a citizen science project in the long-term. Funding will be needed in any citizen science program for either application development, monitoring equipment, or part-time staff members (Bonney et al., 2014; Shirk et al., 2012).

In the initial stages of HOWL, there was very little funding available. NCSU provided resources to acquire some water monitoring equipment and establish the HOWL website. Scant resources limited the extent of the program. However, a year after the program began, NC CES in Onslow County obtained a small grant to obtain additional monitoring equipment. Extension researchers and 4-H staff were also able to dedicate time to coordinate and host several monitoring events. HOWL leaders recognized that they should seek additional funding through grants or potential collaborators to sustain the project for the future. Recruiting, motivating, and retaining volunteers is crucial for success, especially for programs with limited resources. There are a few free database storage networks available, such as iNaturalist and CitSci.org for storing and displaying project data. Citizen science programs can also use social media outlets to promote their project. 


\section{Step 5: Develop, Test, and Use Protocols and Data Forms}

For accurate and precise data, it is necessary to train citizen scientists on standard monitoring protocols. Protocols are formal designs for citizen scientists to follow during data collection (Bonney et al., 2009b). Many citizen scientists lack expertise or experience in research methods and scientific procedures. Thus, protocols should be simple and easily understood by users who may not be familiar with the discipline (Birkin \& Goulson, 2015; Hinckson et al., 2017).

The protocols used for the HOWL project originated from the Izaak Walton League of America (IWLA) Creek Freaks program. Creek Freaks project leaders provided data sheets for citizen scientists to record biological, chemical, and physical water measurements. HOWL citizen scientists complete the forms at each monitoring site and turn them in to someone on the leadership team. HOWL leadership team members review completed data forms to mitigate any errors. Someone with experience in statistics and data analysis will review the forms to observe outliers, which may indicate error. The data forms follow the water monitoring protocols and can then be used in data analysis (Bonney et al., 2009b). For our project, interactive procedures and collection methods encouraged citizen scientist participation.

\section{Step 6: Recruit and Retain}

A persuasive strategy for volunteer recruitment is to relate the project to participants on a personal level (Petty et al., 1981). Those who feel directly responsible for and associated with the project's goals are most likely to participate. Individuals may also want to join because of their interests in contributing to scientific knowledge, making scientific discoveries, collection and dissemination of information, affecting resource stewardship, protecting livelihoods, or satisfying personal identities and learning goals (Phillips et al., 2018; Shirk et al., 2012). According to West \& Pateman (2016), when recruiting collaborators, it is crucial to understand what motivates them to participate. If citizen scientists feel that their needs are respected, they will continue to be involved in the project (Peachey et al., 2014; West \& Pateman, 2016).

Once citizen scientists have been recruited to the project, it is vital to keep them interested and motivated to participate. Motivation is a significant behavioral component and is imperative to generate positive performance (Denhardt et al., 2016). One way to motivate participants is to adopt a goal-setting approach, so that individuals have one or more achievable personal goals they are working toward. Other retention aspects for individuals include community building, social establishment, and relationship enhancement. In addition to motivation tactics, it is important to make sure that each citizen scientist's work and time is valued. Each participant should feel as if his or her work is making a difference in the overall research goals (Phillips et al., 2018).

To gain interest and recruit project membership, the leadership team held a HOWL kick-off event. The event was held at a sampling site and advertised to the community residents and visitors near the Hofmann Forest. The group posted flyers in community centers, schools, websites, and other local meeting 
points in surrounding counties. The event gave a preview of water quality sampling to encourage attendees to become HOWL citizen scientists. The event attracted 60 participants, both children and adults. There was also an extensive write-up prior to the event in the Carteret County News-Times, which helped promote citizen scientist participation and recruitment. Subsequent events held by NC CES have been offered as parent and youth endeavors. Both the parents and the children increased their understanding of local waterways and scientific methods.

\section{Step 7: Train Citizen Scientists}

The training process helps participants to understand, learn about, and follow the scientific method. The training protocols explain the purpose of various data entries and the importance of accurate measurements (Alabri \& Hunter, 2010; Kosmala et al., 2016). The training processes help citizen scientists gain confidence in their data-collection skills (Crall et al., 2010). All citizen scientists must undergo a training session. Creating more scheduled training sessions helps to prevent potential biases or errors in the data (Bonney et al., 2009b). The more credible the data, the better it is perceived by the public, decisionmakers, and grant reviewers (Bowser \& Wiggins, 2015).

HOWL held two 3-hour training sessions at one of the monitoring locations, led by members of the leadership team. The sessions allowed participants to become familiar with the procedures, measurements, and calculations. Short protocol videos were also created and posted on the HOWL website

(http://hofmanncitizenscience.com/). The videos enabled citizen scientists to refresh their understanding of the various water quality sampling methods and to improve their comfort level when taking measurements or training others. The videos demonstrate how to perform the sampling and the equipment needed for each parameter. Following procedures and understanding the processes are crucial for data quality assurance.

\section{Step 8: Analyze the Data}

Once the data are collected, they need to be cleaned and analyzed, preferably by someone with expertise in statistics. Ideally, this responsibility is carried out by a leadership team member. The data manager should act as a steward of the data that are collected, processed, and analyzed, as well as act as an expert validator to clean data before it is evaluated (Kosmala et al., 2016).

Currently, researchers at NC CES and NCSU have primary responsibility for data analyses and distribution. Data are collected via data forms and then translated to both iNaturalist and Google Sheets. iNaturalist is a platform used for data distribution and visualization. Both are free-of-charge platforms. If your citizen scientists collect large-scale data, you should consider upgrading to an advanced database enterprise. IWLA has launched a platform specifically created for the Creek Freaks data (http://www.cleanwaterhub.org/) to make it easier for citizen scientists to post, analyze, and graph data for their monitoring stations, although the Hofmann data are not yet integrated into that site. 


\section{Step 9: Share and Disperse the Results}

The iNaturalist website states that it was created for two goals: "connecting people to nature" and "to generate scientifically valuable biodiversity data from these personal encounters (iNaturalist Network, 2019)." With iNaturalist, citizen scientists can upload data through their smartphones or tablets. A data manager should review the data before posting to the public. Then, community researchers, collaborators, and citizen scientists can view the data. Having such an integrated database provides a data sharing mechanism for researchers, citizen scientists, and non-governmental organizations to offer a new and innovative interdisciplinary opportunity for research and engagement (Newman et al., 2012).

CitSci.org is another free platform (http://www.citsci.org/). Participants can enter sampling methods, location (e.g., latitude and longitude), time and date, and the parameter values (Wang et al., 2015). On the "back-end" side of the platform, a webmaster or a data manager can tailor the attributes and fields to fit the project's scheme. Additional features include mapping, summary statistics, and downloaded datasheets (Wang et al., 2015).

Currently, HOWL posts its data through iNaturalist and the HOWL website (http://hofmanncitizenscience.com/), so that it can be used by researchers and citizen scientists who wish to understand the water quality of the watersheds within eastern North Carolina. In addition to the research community and citizen scientists, the data is available to natural resource managers, practitioners, and decisionmakers. Displaying the data and images allows citizen scientists to see that their collected data is being used (Bonney et al., 2009b). The web presentation of data and dynamic maps, with the ability for citizen scientists to view their observations in near real time, helps build capacity within the network. This contributes to the overall project sustainability and enhances participant retention.

\section{Step 10: Evaluate the Outcomes}

Evaluating participatory research projects serves two purposes: continuing good practices and improving upon specific aspects (Newman et al., 2012). Evaluation is a reflective process to generate knowledge for design, implementation, and recalibration (Kaufman et al., 2014). In this final step, outputs should be measured to assess if scientific, individual, or socio-ecological outcomes of the project were met (Shirk et al., 2012).

Surveys, questionnaires, interviews, focus groups, or a combination of methods may be used to evaluate a project or program. New perceptions and information can be gathered using this multi-method approach. Evaluators can provide a pre-survey or questionnaire before citizen scientists participate in the project. Such pre-surveys can collect information on the participants' initial objectives or goals (i.e., individual outcomes) that they wish to achieve when working on the project, as well as what motivates them to participate (West \& Pateman, 2016). A simple pre-survey or quiz could also gain insight into how 
much a participant knows about scientific processes and content before participating in the project. Then, a follow-up should be given to evaluate a participant's knowledge of experimental procedures and subjects after a year (or less) participating in the project (Bonney et al., 2009b). Collecting this information early-on can help the leadership team assist citizen scientists in meeting their individual goals and tracking their progress overtime.

For HOWL, the socio-ecological and participant outcomes of the project were evaluated through brief interviews with the citizen scientists. The evaluation was useful to gain critical feedback for the sustainability and longevity of the project. However, the water quality data have not yet been evaluated. Assessing the data collected by HOWL citizen scientists is the next step in the evaluation process. Soon, HOWL researchers will also review the number of participants and collaborators involved over the project's lifespan.

\section{Discussion and Conclusion}

This paper describes the development and application of a forest-based citizen science project in the Coastal Plain of eastern North Carolina. Forest sites offer excellent locations for citizen science efforts, since they can help compare relatively pristine conditions, wildlife, and water quality on the forests with adjacent more-developed lands. Congruently, the citizen science efforts can examine hypotheses about whether such forest sites achieve the presumed high-quality natural conditions, biodiversity, and ecosystem functions that are expected.

The citizen science efforts near the Hofmann Forest in Eastern North Carolina provided an excellent case study of the development of citizen science on the forest and adjacent lands. The Hofmann is quite unique, being the largest university education and research forest in the US, as well as an intensively managed pine plantation forest. The mix of plantation forests, active management, and natural wetlands presents a unique site for citizen science and will eventually allow HOWL to examine the impacts of forest management practices after baseline data are obtained. The initial efforts to start the Hofmann Open Water Laboratory (HOWL) citizen programs stemmed from the threatened commercial sale of the forest and proposed agricultural or housing development of the site. Water quality of more developed land uses also can be measured and compared to the Hofmann runoff. HOWL initially examined water quality emanating from the forest as its primary focus and prospered as a loose network of citizens and interest groups with joint scientific, educational, and advocacy interests. The focus of HOWL has shifted a bit, as citizen scientists were interested in the quality of waterways near where they lived.

This paper defines ten steps that can be used by professional researchers, non-professional researchers, practitioners, environmental educators, and forest managers to utilize citizen science efforts in management, monitoring, and research projects. It also discusses how these steps played out in the case of HOWL and made observations and suggestions about achieving success in such an ef- 
fort. The guidelines we have discussed can be followed to create any type of project-co-created, collaborative, or contributory-as well as for a variety of outcomes. Motivated through a shared goal, citizen scientists work together to assemble a diverse variety of ideas, expertise, and support that can create successful outcomes (Savage et al., 2018). The guidelines present suggestions for productive and enduring processes for citizen engagement and project sustainability. Each project will need its participants to set their own goals, continue to build a diverse collaboration, and most importantly, establish on-going evaluation processes to determine successful and failed components that ensures the project moves forward effectively.

Like other forest-based citizen science efforts (e.g., McKinley et al., 2017; Pitt \& Schultz, 2018), HOWL attempts to meet participant and socio-ecological outcomes, such as encouraging public action in natural resource and forest management, as well as enhancing scientific knowledge and skills. Additionally, like other programs, HOWL utilizes citizen scientists to monitor the water quality within the forest (e.g., Alabama Water Watch Program (McKinley et al., 2017)). However, unlike other citizen science projects focused in a forest context, HOWL has been developed simultaneously by non-professional researchers in the local community and professional researchers to meet the project's outcomes. HOWL relies on citizen scientists, of all ages, to monitor both the water quality and quantity that flows on and off the forest.

This project has generated considerable enthusiasm and participation in its first two years of effort. Field days had less participation in the last year, so maintaining participation will be the key to long term sustainability and success. We will continue to pursue these cooperative efforts, and monitor progress in the coming years. The effect of the citizen science is unclear. The collaboration is fairly new, and it remains to be determined if the project is enduring. However, future work is being done by NC State University researchers to provide the findings from the HOWL water quality and quantity data. Additional research is currently conducted to understand the socio-ecological and participant outcomes from the project.

Local citizens, environmental groups, and university scientists cooperated to develop the Hofmann Outdoor Water Lab (HOWL) around the Hofmann Forest in eastern North Carolina. HOWL citizen scientists will continue to seek to understand the role and importance of the Hofmann Forest in the inner-coastal plain of the state by monitoring the water quality, and quantity, that flows on and off the managed forest. HOWL not only aimed to achieve this scientific outcome, but also, to increase community networking, build community engagement, increase participants' perceptions of stewardship, and enhance environmental education, all within a forest landscape. The project helps synthesize our experiences in this effort and the social science literature, providing reasonable guidelines for those seeking to establish their own citizen science efforts within a forest context. 


\section{Conflicts of Interest}

The authors declare no conflicts of interest regarding the publication of this paper.

\section{References}

Alabri, A., \& Hunter, J. (2010). Enhancing the Quality and Trust of Citizen Science Data. In IEEE Sixth International Conference on e-Science (pp. 81-88). Piscataway, NJ: Institute of Electrical and Electronics Engineers. https://doi.org/10.1109/eScience.2010.33

Ballard, H. L., Trettevick, J. A., \& Collins, D. (2008). Comparing Participatory Ecological Research in Two Contexts: An Immigrant Community and a Native American Community on Olympic Peninsula, Washington. In C. Wilmsen, W. Elmendorf, L. Fisher, J. Ross, B. Sararthy, \& G. Wells (Eds.), Partnerships for Empowerment: Participatory Research for Community-Based Natural Resource Management (pp. 187-215). London: Earthscan.

Bell, S., Marzano, M., Cent, J., Kobierska, H., Podjed, D., Vandzinskaite, D. et al. (2008). What Counts? Volunteers and Their Organisations in the Recording and Monitoring of Biodiversity. Biodiversity and Conservation, 17, 3443-3454. https://doi.org/10.1007/s10531-008-9357-9

Bennett, L. M., Gadlin, H., \& Levine-Finley, S. (2010). Collaboration and Team Science: A Field Guide. Bethesda: National Institutes of Health.

Birkin, L., \& Goulson, D. (2015). Using Citizen Science to Monitor Pollination Services. Ecological Entomology, 40, 3-11. https://doi.org/10.1111/een.12227

Blair, R. B., Forston, L., Anderson, A., \& Strauss, A. (2018). Recommendations for the Creation of a Center for Citizen Science. Journal of Extension, 56, Article 4FEA4. https://joe.org/joe/2018august/a4.php

Bonney, R., Ballard, H., Jordan, R., McCallie, E., Phillips, T., Shirk, J., \& Wilderman, C. C. (2009a). Public Participation in Scientific Research: Defining the Field and Assessing Its Potential for Informal Science Education. A CAISE Inquiry Group Report. Washington DC: Center for Advancement of Informal Science Education (CAISE).

Bonney, R., Cooper, C. B., Dickinson, J., Kelling, S., Phillips, T., Rosenberg, K. V., \& Shirk, J. (2009b). Citizen Science: A Developing Tool for Expanding Science Knowledge and Scientific Literacy. BioScience, 59, 977-984. https://doi.org/10.1525/bio.2009.59.11.9

Bonney, R., Shirk, J., Phillips, T., Wiggins, A., Ballard, H., Miller, A., \& Parrish, J. (2014). Next Steps for Citizen Science. Science, 343, 1436-1437. https://doi.org/10.1126/science.1251554

Bowser, A., \& Wiggins, A. (2015). Privacy in Participatory Research: Advancing Policy to Support Human Computation. Human Computation, 2, 19-44.

https://doi.org/10.15346/hc.v2i1.3

Burns, M., Smith, M., Slade, E., \& Ennos, R. (2014). The Saproxylic Activity Index: A New Tool for the Rapid Assessment of Deadwood Species during Forest Restoration. Open Journal of Forestry, 4, 144-150. https://doi.org/10.4236/ojf.2014.42020

Cooper, C. B., Dickinson, P. T., \& Bonney, R. (2007). Citizen Science as a Tool for Conservation in Residential Ecosystems. Ecology and Society, 12, 11. https://doi.org/10.5751/ES-02197-120211

Crall, A. W., Newman, G. J., \& Jarnevich, C. S. (2010). Improving Citizen Science as a Tool for Biodiversity Monitoring. Biological Invasions, 12, 3419.

https://doi.org/10.1007/s10530-010-9740-9

Cubbage, F., Roise, J., \& Sutherland, R. (2016). The Proposed Sale of the Hofmann Forest: 
A Case Study in Natural Resource Policy. In Forest Economics and Policy in a Changing Environment: How Market, Policy, and Climate Transformations Affect Forests, Proceedings of the 2016 Meeting of the International Society of Forest Resource Economics (pp. 81-93). Forest Service Southern Research Station e-General Technical Report SRS-218. http://sofew.cfr.msstate.edu/papers/cubbage16.pdf

Davies, A., \& White, R. (2012). Collaboration in Natural Resource Governance: Reconciling Stakeholder Expectations in Deer Management in Scotland. Journal of Environmental Management, 112, 160-169. https://doi.org/10.1016/j.jenvman.2012.07.032

Denhardt, R. B., Denhardt, J. V., \& Aristigueta, M. P. (2016). Motivation and Engagement. In Managing Human Behavior in Public and Nonprofit Organizations (pp. 153174). Thousand Oaks, CA: SAGE Publications.

Dickinson, J. L., Shirk, J., Bonter, D., Bonney, R., Crain, R. L., Martin, J., Phillips, T., \& Purcell, K. (2012). The Current State of Citizen Science as a Tool for Ecological Research and Public Engagement. Frontiers in Ecology and the Environment, 10, 291-297. https://doi.org/10.1890/110236

Dickinson, J., Zuckerberg, B., \& Bonter, D. (2010). Citizen Science as an Ecological Research Tool: Challenges and Benefits. Annual Review of Ecology, Evolution, and Systematics, 41, 149-172. https://doi.org/10.1146/annurev-ecolsys-102209-144636

Edwards, B., \& Driscoll, A. (2008). From Farms to Factories: The Environmental Consequences of Swine Industrialization in North Carolina. In K. A. Gould, \& T. L. Lewis (Eds.), Twenty Lessons in Environmental Sociology (pp. 153-175). New York: Oxford University Press.

Government Accountability Office (2008). Concentrated Animal Feeding Operations. EPA Needs More Information and a Clearly Defined Strategy to Protect Air and Water Quality from Pollutants of Concern. Report to Congressional Requesters.

Haklay, M. (2013). Citizen Science and Volunteered Geographic Information: Overview and Typology of Participation. In D. Sui, S. Elwood, \& M. Goodchild (Eds.), Crowdsourcing Geographic Knowledge (pp, 105-122). Dordrecht: Springer. https://doi.org/10.1007/978-94-007-4587-2 7

Hawthorne, T., Elmore, V., Strong, A., Bennett-Martin, P., Finnie, J., Parkman, J., Harris, T., Singh, J., Edwards, L., \& Reed, J. (2015). Mapping Non-Native Invasive Species and Accessibility in an Urban Forest: A Case Study of Participatory Mapping and Citizen Science in Atlanta, Georgia. Applied Geography, 56, 187-198.

https://doi.org/10.1016/j.apgeog.2014.10.005

Hinckson, E., Schneider, M., Winter, S. J., Stone, E., Puhan, M., Stathi, A., \& King, A. C. (2017). Citizen Science Applied to Building Healthier Community Environments: Advancing the Field through Shared Construct and Measurement Development. International Journal of Behavioral Nutrition and Physical Activity, 14, Article No. 133. https://doi.org/10.1186/s12966-017-0588-6

Huffman, R. L., \& Westerman, P. W. (1995). Estimated Seepage Losses from Established Swine Waste Lagoons in the Lower Coastal Plain of North Carolina. Transactions of the ASAE, 38, 449-453. https://doi.org/10.13031/2013.27852

iNaturalist Network (2019). How It Works. https://www.inaturalist.org/pages/about

Ingell, L., \& Preisser, E. (2011). Using Citizen Science Programs to Identify Host Resistance in Pest-Invaded Forests. Conservation Biology, 25, 182-188.

https://doi.org/10.1111/j.1523-1739.2010.01567.x

Kaufman, S., Ozawa, C. P., \& Shmueli, D. F. (2014). Evaluating Participatory Decision Processes: Which Methods Inform Reflective Practice? Evaluation and Program Planning, 42, 11-20. https://doi.org/10.1016/j.evalprogplan.2013.08.002 
Kosmala, M., Wiggins, A., Swanson, A., \& Simmons, B. (2016). Assessing Data Quality in Citizen Science. Frontiers in Ecology and the Environment, 14, 551-560. https://doi.org/10.1002/fee.1436

Krasny, M., \& Doyle, R. (2002). Participatory Approaches to Program Development and Engaging Youth in Research: The Case of an Inter-Generational Urban Community Gardening Program. Journal of Extension, 40, 5FEA3.

McGreavy, B., Calhoun, A. J. K., Jansujwicz, J., \& Levesque, V. (2016). Citizen Science and Natural Resource Governance: Program Design for Vernal Pool Policy Innovation. Ecology and Society, 21, 48. https://doi.org/10.5751/ES-08437-210248

McKinley, D., Briggs, R., \& Bartuska, A. (2012). When Peer-Reviewed Publications Are Not Enough! Delivering Science for Natural Resource Management. Forest Policy and Economics, 21, 1-11. https://doi.org/10.1016/j.forpol.2012.03.007

McKinley, D., Miller-Rushing, A., Ballard, H., Bonney, R., Brown, H., Cook-Patton, S., Evans, D., French, R., Parrish, J., Phillips, T., Ryan, S., Shanley, L., Shirk, J., Stepenuck, K., Weltzin, J., Wiggins, A., Boyle, O., Briggs, R., Chapin, S., Hewitt, D., Preuss, P., \& Soukup, M. (2017). Citizen Science Can Improve Conservation Science, Natural Resource Management, and Environmental Protection. Biological Conservation, 208, 15-28. https://doi.org/10.1016/j.biocon.2016.05.015

Montgomery, A., \& Sutherland, R. (2016). The Importance of Hofmann Forest Interactive Map. Wildlands Network.

https://www.arcgis.com/apps/MapTour/index.html?appid=80da886a8e7e4eb899a4d3e9 c11c66bd\&webmap=f7f74fe9ea9347df91911cd45f6f0755

Newman, G., Wiggins, A., Crall, A., Graham, E., Newman, S., \& Crowston, K. (2012). The Future of Citizen Science: Emerging Technologies and Shifting Paradigms. Frontiers in Ecology and the Environment, 10, 298-304. http://www.jstor.org/stable/41811393 https://doi.org/10.1890/110294

Ottinger, G. (2009). Buckets of Resistance: Standards and the Effectiveness of Citizen Science. Science, Technology, \& Human Values, 35, 244-270.

http://journals.sagepub.com/doi/abs/10.1177/0162243909337121 https://doi.org/10.1177/0162243909337121

Peachey, J. W., Lyras, A., Cohen, C., Bruening, J. E., \& Cunningham, G. B. (2014). Exploring the Motives and Retention Factors of Sport-for-Development Volunteers. Nonprofit and Voluntary Sector Quarterly, 43, 1052-1069.

https://doi.org/10.1177/0899764013501579

Petty, R. E., Cacioppo, J. T., \& Goldman, R. (1981). Personal Involvement as a Determinant of Argument-Based Persuasion. Journal of Personality and Social Psychology, 41, 847. https://doi.org/10.1037/0022-3514.41.5.847

Phillips, T., Porticella, N., Constas, M., \& Bonney, R. (2018). A Framework for Articulating and Measuring Individual Learning Outcomes from Participation in Citizen Science. Citizen Science: Theory and Practice, 3, 3. https://doi.org/10.5334/cstp.126

Pitt, A., \& Shultz, C. (2018). Youth-Based Citizen Science Monitoring: Case Studies from Three National Forests. Journal of Forestry, 116, 109-116.

https://doi.org/10.1093/jofore/fvx008

Ramirez-Andreotta, M., Brusseau, M. L., Artiola, J., Maier, R. M., \& Gandolfi, A. J. (2015). Building a Co-Created Citizen Science Program with Gardeners Neighboring a Superfund Site: The Garden Roots Case Study. International Public Health Journal, 7. https://proxying.lib.ncsu.edu/index.php/login?url=https://search-proquest-com.prox.li b.ncsu.edu/docview/1826616553?accountid $=12725$

Savage, A., Bruno, S., Hovis, M., Spencer, S. E., Dinan, M., \& Seekamp, E. (2018). Work- 
ing Together: A Guide to Collaboration in Rural Revitalization. NC State University Extension Publications.

https://content.ces.ncsu.edu/working-together-a-guide-to-collaboration-in-rural-revita lization

Schusler, T. M., \& Krasny, M. E. (2008). Youth Participation in Local Environmental Action: An Avenue for Science and Civic Learning? In Participation and Learning (pp. 268-284). Dordrecht: Springer. https://doi.org/10.1007/978-1-4020-6416-6 17

Shirk, J., Ballard, H., Wilderman, C., Philips, T., Wiggins, A., Jordan, R., McCallie, E., Minarchek, M., Lewenstein, B., Krasny, M., \& Bonney, R. (2012). Public Participation in Scientific Research: A Framework for Deliberate Design. Ecology and Society, 17, 29. https://doi.org/10.5751/ES-04705-170229

Stern, M., \& Predmore, A. (2012). The Importance of Team Functioning to Natural Resource Planning Outcomes. Journal of Environmental Management, 106, 30-39. https://doi.org/10.1016/j.jenvman.2012.03.049

Tarter, K. D., Levy, C. E., Yaglom, H. D., Adams, L. E., Plante, L., Casal, M. G., \& Walker, K. R. (2019). Using Citizen Science to Enhance Surveillance of Aedes Aefypti in Arizona, 2015-17. Journal of the American Mosquito Control Association, 35, 11-18. https://proxying.lib.ncsu.edu/index.php/login?url=https://search-proquest-com.prox.li b.ncsu.edu/docview/2203051438?accountid $=12725$ https://doi.org/10.2987/18-6789.1

Tyson, A. (2019). NOLS and Nutcrackers: The Motivations, Barriers, and Benefits Experienced by Outdoor Adventure Educators in the Context of a Citizen Science Project. Citizen Science: Theory and Practice, 4, 19. https://doi.org/10.5334/cstp.127

US Fish \& Wildlife Service (2018). Endangered and Threatened Species and Species of Concern by County for North Carolina. https://www.fws.gov/raleigh/species/cntylist/nc counties.html

US Geological Survey (2018). Water Resources of the South Atlantic Water Science Center. https://nc.water.usgs.gov/realtime/index.html

Vohland, K., Weibpflug, M., \& Pettibone, L. (2019). Citizen Science and the Neoliberal Transformation of Science: An Ambivalent Relationship. Citizen Science: Theory and Practice, 4, 25. https://doi.org/10.5334/cstp.186

Walpole, E., Toman, R., Wilson, S., \& Stidham, M. (2017). Shared Visions, Future Challenges: A Case Study of Three Collaborative Forest Landscape Restoration Program Locations. Ecology and Society, 22, 35. https://doi.org/10.5751/ES-09248-220235

Wang, Y., Kaplan, N., Newman, G., \& Scarpino, R. (2015). A New Model for Managing, Documenting, and Sharing Citizen Science Data. PLOS Biology, 13, e1002343. https://doi.org/10.1371/journal.pbio.1002280

Watkins, C., Zavaleta, J., Wilson, S., \& Francisco, S. (2018). Developing an Interdisciplinary and Cross-Sectoral Community of Practice in the Domain of Forests and Livelihoods. Conservation Biology, 32, 60-71. https://doi.org/10.1111/cobi.12982

West, S., \& Pateman, R. (2016). Recruiting and Retaining Participants in Citizen Science: What Can Be Learned from the Volunteering Literature? Citizen Science: Theory and Practice, 1, 15. https://doi.org/10.5334/cstp.8

Wondolleck, J. M., \& Yaffee, S. L. (2000). Making Collaboration Work: Lessons from Innovation in Natural Resource Management. Washington DC: Island Press. 